\title{
Determination of the Overturning Torque of the Cutting Forces of the Knife Actuating Device of the Geokhod
}

\author{
Vladimir Aksenov ${ }^{1,3}$, Vladimir Sadovets ${ }^{2 *}$, Vyacheslav Beglyakov ${ }^{2,4}$, Dmitry Pashkov ${ }^{2,3}$, and \\ Elena Rezanova ${ }^{2}$ \\ ${ }^{1}$ Research Center "Siberian NPO", 650000 Sovetsky av., 56, Kemerovo, Russia \\ ${ }^{2}$ T.F. Gorbachev Kuzbass State Technical University, 650000 Vesennyaya st. 28, Kemerovo, Russia \\ ${ }^{3}$ Institute of Coal of the Federal Research Center Coal and Coal Chemistry Siberian Branch of the \\ RAS, 650610 Leningradsky av. 10, Kemerovo, Russia \\ ${ }^{4}$ Yurga Technological Institute (branch) of the National Research Tomsk Polytechnic University, \\ 652055, 26 Leningradskaya st., Yurga, Kemerovo region, Russia
}

\begin{abstract}
The paper considers the relevance of the research, indicated by the authors in the title of the article. As a result of the studies carried out, it was found that the overturning torque of the cutting forces occurs as a result of the imbalance of the system of cutting forces during the destruction of rocks by the actuating device of the geokhod. It was revealed that the value of the critical overturning torque of cutting forces is influenced by two force factors; this is the projection of the resistance of the soil to cutting on a plane perpendicular to the axis of rotation, as well as the total moment of resistance to cutting. As a result of the study, the critical values of the withdrawal force and overturning torque were obtained for specific mining conditions for the development and the specified geometric parameters of the actuating device of the geokhod. The resulting withdrawal force during the destruction of the face rock by the actuating device causes a deviation of the axis of geokhod rotation from the axis of the working's route. Therefore, it becomes necessary to constantly monitor the deviation of the geokhod rotation axis from the axis of the working's route, and, if necessary, to correct the geokhod displacement.
\end{abstract}

\section{Introduction}

With the increase in the use of underground space for human needs, it is necessary to increase the volume of construction of underground useful spaces [1-5]. This, in turn, creates the prerequisites for an increase in the productivity of equipment.

As a result of a number of studies aimed at increasing productivity, a new approach to the construction of underground structures has been formed - geo-winchester technology, the basic element of which is a new class of mining equipment - the geokhod [6-13].

\footnotetext{
*Corresponding author: vsadovec@yandex.ru
} 
One of the main functional elements for underground construction is the actuating device $(\mathrm{AD})$ of the tunneling machine [14-19].

When the geokhod moves along the working's route, force factors inevitably arise, which are formed during the destruction of rock with a knife $\mathrm{AD}$, which will affect the trajectory of the penetrating machine and its deviation from the working's route. Such the main factor is the overturning torque of the cutting forces, which arises as a result of the imbalance of the system of cutting forces during the destruction of rocks. As a result, a study aimed at determining the overturning torque of the cutting forces of the knife actuating device of the geokhod is relevant.

\section{Research Method}

The overturning torque of the cutting forces occurs with a sharp increase in the cutting force on the actuating device of the external mover. Its critical value will be determined in the event of jamming of the cutting element cutting the helical channel.

In earlier studies [20-22], the main force parameters of the destruction of the geokhod's knife $\mathrm{AD}$ are the projection of the component of the soil resistance to cutting, depending on the cut width, onto the axis of rotation of the geokhod $P_{o}^{c u t}$, the projection of the resistance of the soil to cutting onto a plane perpendicular to the axis of rotation $R_{\text {res }}^{\text {cut }}$, as well as the total moment of resistance to cutting $M_{\text {res }}^{\text {cut }}$.

To determine the critical value of the overturning torque, we will take one of the design solutions of the knife $\mathrm{AD}$, which consists of one knife $\mathrm{AD}$ of the face and $\mathrm{AD}$ of the external propeller (Figure 1). The geometrical parameters of the actuating device and the mining conditions for carrying out underground structures are presented in Table 1.

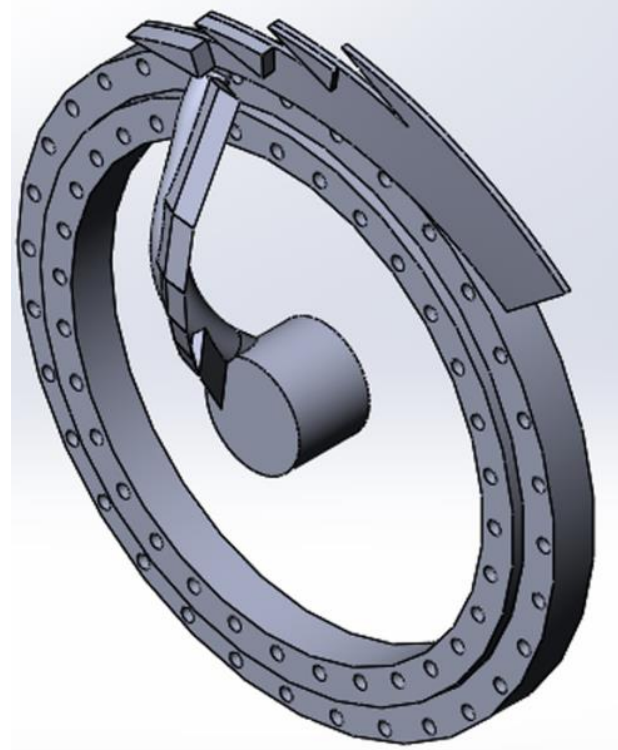

Fig. 1. Scheme of the actuating device of the geokhod.

\section{Results}

When determining the critical forces acting on one blade $\mathrm{AD}$ of the face and $\mathrm{AD}$ of the external propeller, we will not take into account the projection of the component of the soil cutting resistance force, which depends on the cut width, on the axis of rotation of the 
geokhod (since the action of this component of the cutting force lies in the plane perpendicular to the plane of action of the overturning torque (Figure 2)). In addition, the determination of the critical forces will be carried out according to the obtained expressions [23-24] for knives that have a wear area.
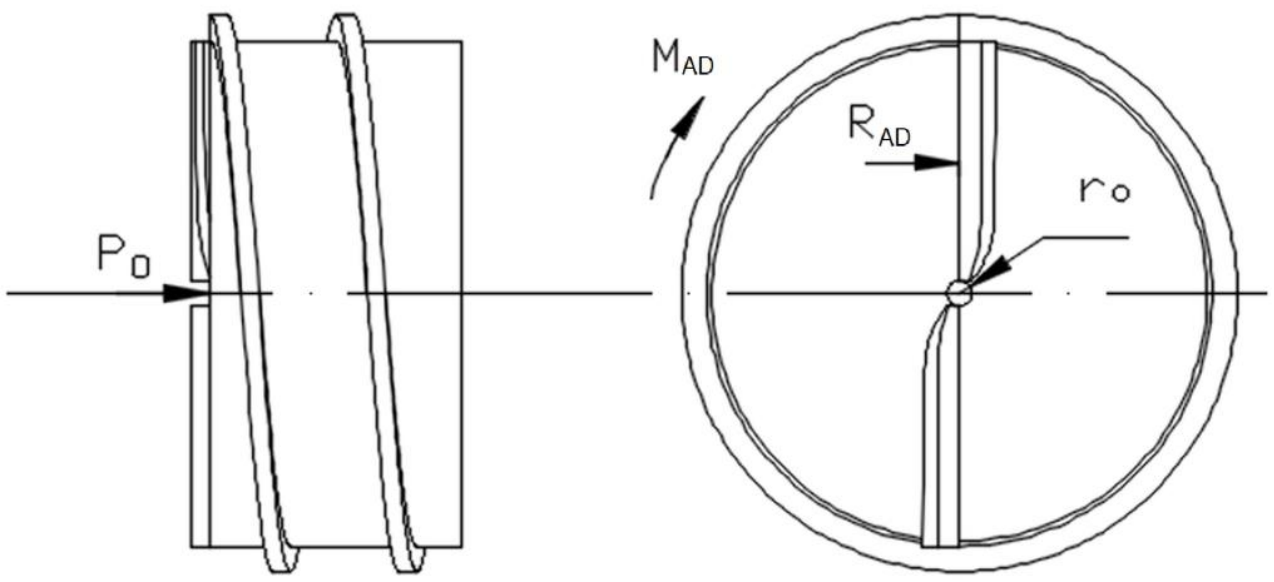

Fig. 2. Design scheme for determining the total force of soil resistance to cutting by a knife actuating device.

Table 1. Geometric parameters of the actuating device and mining conditions for the working development.

\begin{tabular}{|c|c|c|c|}
\hline Parameter & Designation & $\begin{array}{c}\text { Unit of } \\
\text { measurement }\end{array}$ & Value \\
\hline $\begin{array}{c}\text { Radius of the generatrix of the sphere of } \\
\text { the actuating device }\end{array}$ & $r_{o}$ & $\mathrm{~m}$ & 0.025 \\
\hline Geokhod radius & $r_{g}$ & $\mathrm{~m}$ & 0.32 \\
\hline $\begin{array}{c}\text { External mover step } \\
\text { distance } r_{g}\end{array}$ & $h_{b}$ & $\mathrm{~m}$ & 0.1 \\
\hline $\begin{array}{c}\text { The angle of movement of the knife } \\
\text { point AD of the geokhod located at a }\end{array}$ & $\beta_{1}$ & deg & 8.8 \\
\hline $\begin{array}{c}\text { The angle of movement of the point of } \\
\text { the geokhod knife AD located at a dis- } \\
\text { tance } r_{o}\end{array}$ & $\beta_{2}$ & 87.7 \\
\hline $\begin{array}{c}\text { Coefficient taking into account the influ- } \\
\text { ence of the cutting angle }\end{array}$ & $\varphi$ & $\mathrm{N} / \mathrm{m}^{2}$ & 31000 \\
\hline $\begin{array}{c}\text { Specific cutting force in the frontal part } \\
\text { of the slot at a cutting angle of } 45^{0}\end{array}$ & $m_{\text {cut }}$ & $\mathrm{N} / \mathrm{m}^{2}$ & 9000 \\
\hline $\begin{array}{c}\text { The force of destruction of soil in the } \\
\text { lateral parts of the cut }\end{array}$ & $m_{\text {side }}$ & $\mathrm{N} / \mathrm{m}^{2}$ & 740 \\
\hline $\begin{array}{c}\text { Specific cutting force of one of the side } \\
\text { edges of the knife }\end{array}$ & $m_{\text {side }}$ & & 0.78 \\
\hline
\end{tabular}




\begin{tabular}{|c|c|c|c|}
\hline Parameter & Designation & $\begin{array}{c}\text { Unit of } \\
\text { measurement }\end{array}$ & Value \\
\hline $\begin{array}{l}\text { The angle of the radial knife inclination } \\
\text { to the plane perpendicular to the axis of } \\
\text { geokhod rotation }\end{array}$ & $\gamma$ & deg & 0 \\
\hline Cutting angle & $\delta$ & deg & 25 \\
\hline Number of AD knife beams & $n$ & & 1 \\
\hline Knife friction angle & $\varphi_{f r}$ & deg & 31.4 \\
\hline $\begin{array}{c}\text { Angle of friction of soil against external } \\
\text { mover }\end{array}$ & $\mu$ & deg & 31.4 \\
\hline $\begin{array}{l}\text { Additional cutting force that must be } \\
\text { applied to a knife with wear area or } \\
\text { bluntness }\end{array}$ & $P_{\text {wear }}$ & $\mathrm{N} / \mathrm{m}$ & 61900 \\
\hline $\begin{array}{l}\text { Additional cutting force that must be } \\
\text { applied to an external mover with a wear } \\
\text { area or bluntness }\end{array}$ & $P^{\prime}{ }_{w \cdot a r}$ & $\mathrm{~N} / \mathrm{m}$ & 61900 \\
\hline Cutting depth & $h$ & $\mathrm{~m}$ & 0.1 \\
\hline
\end{tabular}

For one knife AD of a geokhod, which has a wear area, the projection of the soil resistance to cutting on a plane perpendicular to the axis of rotation, as well as the total moment of resistance to cutting, respectively, are equal to [23-24]:

$$
\begin{aligned}
& \left.R_{\text {res }}^{c u t}=\frac{\varphi m_{\text {cut }} h_{b}^{2}+h_{b} n P_{\text {wear }}}{2 \pi n \cos \gamma} \cdot \frac{\sin \beta_{2}-\sin \beta_{1}}{\sin \beta_{1} \sin \beta_{2}}+\frac{h_{b}}{2 \pi}\left(\varphi m_{\text {cut }} \frac{h_{b}}{n} \frac{\operatorname{ctg}\left(\delta+\varphi_{f r}\right)}{\cos \gamma}-\frac{\operatorname{ctg}\left(\delta+\varphi_{f r}\right)}{\cos \gamma} P_{\text {wear }}\right) \cdot \ln \frac{\operatorname{tg}\left|\frac{\beta_{2}}{2}\right|}{\operatorname{tg}\left|\frac{\beta_{1}}{2}\right|}\right) \\
& M_{\text {res }}^{c u t}=\frac{\varphi m_{c u t} h_{b}^{3}+h_{b}^{2} n P_{\text {wear }}}{8 \pi^{2} n \cos \gamma}\left(\ln \left|\frac{\operatorname{tg} \frac{\beta_{1}}{2}}{\operatorname{tg} \frac{\beta_{2}}{2}}\right|+\frac{\cos \beta_{2} \sin ^{2} \beta_{1}-\cos \beta_{1} \sin ^{2} \beta_{2}}{\sin ^{2} \beta_{1} \sin ^{2} \beta_{2}}\right)+ \\
& +\frac{h b}{4 \pi^{2}}\left(\varphi m_{c u t} \frac{h_{b}}{n} \frac{\operatorname{ctg}\left(\delta+\varphi_{f r}\right)}{\cos \gamma}-\frac{\operatorname{ctg}\left(\delta+\varphi_{f r}\right)}{\cos \gamma} P_{\text {wear }}\right) \cdot \frac{\sin \beta_{2}-\sin \beta_{1}}{\sin \beta_{1} \sin \beta_{2}}
\end{aligned}
$$

Substituting the values of the input parameters given in Table 1 into the presented expressions, we obtain the values of the critical cutting forces:

$$
R_{\text {res }}^{\text {cut }}=673.9 \mathrm{~N} \text { и } M_{\text {res }}^{\text {cut }}=111.1 \mathrm{Nm}
$$

The expressions for determining the forces in the lateral cuts in destruction with a knife $\mathrm{AD}$ with a wear area are presented below [23-24]: 


$$
\begin{gathered}
R_{\text {cut.side }}=\frac{h_{b}}{n}\left(m_{\text {side }} \frac{h_{b}}{n}+m_{\text {side.cut }}\right)\left[\frac{\sin \left(\delta+\varphi_{f r}+\beta_{1}\right)+\sin \left(\delta+\varphi_{f r}+\beta_{2}\right)}{\sin \left(\delta+\varphi_{f r}\right)}\right] \\
M_{\text {cut.side }}=\frac{h_{b}}{n}\left(m_{\text {side }} \frac{h_{B}}{n}+m_{\text {side.cut }}\right)\left[\frac{r_{g} \sin \left(\delta+\varphi f r+\beta_{1}\right)+r_{o} \sin \left(\delta+\varphi_{f r}+\beta_{2}\right)}{\sin \left(\delta+\varphi_{f r}\right)}\right]
\end{gathered}
$$

Substituting the values of the input parameters presented in Table 1 into the presented expressions, we obtain the values of the critical cutting forces:

$$
R_{\text {cut.side }}=42.3 \mathrm{~N} \text { и } M_{\text {cut.side }}=6.4 \mathrm{Nm}
$$

The value of the total projection of the forces and the moment of resistance of the soil to cutting with a knife $\mathrm{AD}$, destructing the face:

$$
\begin{gathered}
R_{A D}=\left(R_{\text {res }}^{\text {cut }}+R_{\text {cut.side }}\right)=716.2 \mathrm{~N} \\
M_{A D}=\left(M_{\text {res }}^{\text {cut }}+M_{\text {cut.side }}\right)=117.5 \mathrm{~N}
\end{gathered}
$$

For the knife, the cutting helical channel behind the working contour, the cutting forces, taking into account the wear of the cutting element, will be equal [23-24]:

$$
\begin{gathered}
R_{A D}^{\prime}=b\left[\varphi m_{c u t} h(\cos \beta+\operatorname{ctg}(\delta+\mu))+\operatorname{ctg}(\delta+\mu) p_{w . a r}^{\prime}\right]+ \\
+2 h\left(m_{\text {side }} h+m_{\text {side.cut }}\right) \cdot(\operatorname{ctg}(\delta+\mu)+\cos \beta) \\
M_{A D}^{\prime}=b\left(r_{1}+\frac{h}{2}\right)\left[\varphi m_{\text {cut }} b h \cos \beta+p_{\text {w.ar }}^{\prime}\right]+2 h \cos \beta\left(r_{1}+\frac{h}{2}\right)+\left(m_{\text {side }} h+m_{\text {side.cut }}\right)
\end{gathered}
$$

After setting the geometrical parameters of the actuating device and the mining and technical conditions for the development in expressions (5) and (6), we get:

$$
R_{A D}^{\prime}=724.2 \mathrm{~N} \text { и } M_{A D}^{\prime}=162.8 \mathrm{Nm}
$$

The critical overturning torque relative to point $A$ of the geokhod (Figure 3), which occurs when the conditions $h=h_{b}$ and $n=1$ are met, will be determined by the expression:

$$
\begin{gathered}
M_{c r}=M_{A D}+M_{A D}^{\prime}+R_{o} \cdot \frac{3}{4} D_{g}+R^{\prime}{ }_{o} \cdot D_{g} \\
M_{c r}=117.5+162.8+716.2 \cdot \frac{3}{4} 0.64+724.2 \cdot 0.64=1087.6 \mathrm{Nm}
\end{gathered}
$$




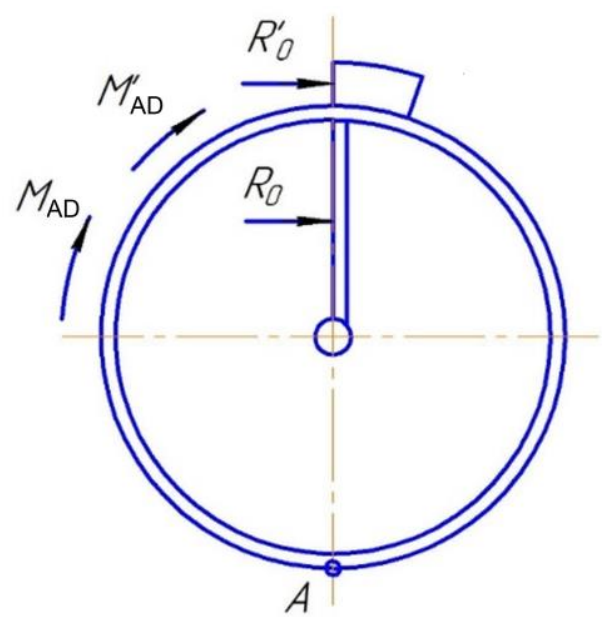

Fig. 3. Design scheme to determine the critical cutting forces.

The scheme for determining the direction of the critical overturning torque is shown in Figure 4 , in which the torque is presented in the form of a pair of forces $F_{c r}-F^{\prime}{ }_{c r}$. The direction of the critical overturning torque is counterclockwise. This torque can be represented as a pair of forces $F_{c r}-F^{\prime}{ }_{c r}$ centered at point $A$. Substituting the previously obtained value of the critical torque and the specified value of the diameter of the geokhod, we get:

$$
\begin{gathered}
F_{c r}=\frac{M_{c r}}{D_{g}} \\
F_{c r}=\frac{1087.6}{0.64}=1699.4 \mathrm{~N}
\end{gathered}
$$

The force acting on the shell of the traction section (at point $A$ ) when $\mathrm{AD}$ of external propeller is jammed, will be determined along the line of distribution of critical cutting forces (Figure 4). This force will affect the deviation of the axis of rotation of the geokhod from the axis of the roadway; let's call it the critical withdrawal force. Its value for the conditions presented in Table 1 will be equal to:

$$
F_{c r w}=\frac{F_{c r}}{2}=\frac{1699.4}{2}=849.7 \mathrm{~N}
$$



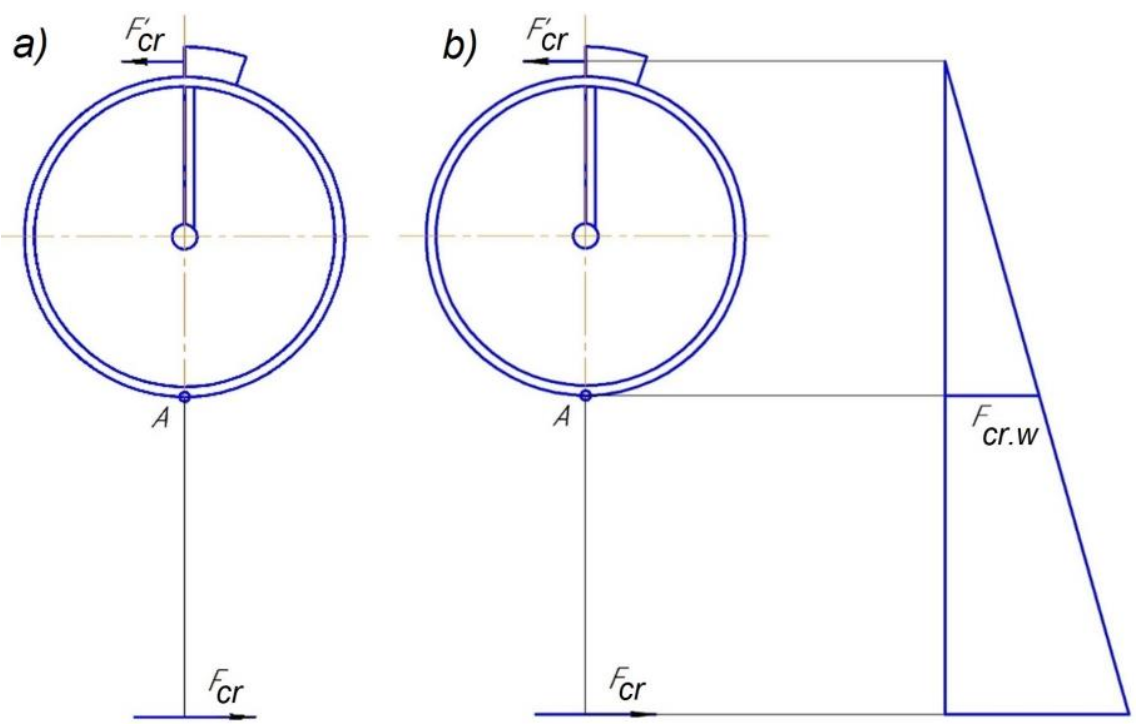

Fig. 4. Determination of the direction of the overturning force (a) and plotting the critical cutting force distribution line (b).

The design scheme of geokhod's knife AD has four knives. The knife AD of the face geokhod can be considered self-balanced, since its rays are located symmetrically relative to the axis of rotation of the geokhod. The design scheme of the overturning torque will take the form shown in Figure 5.

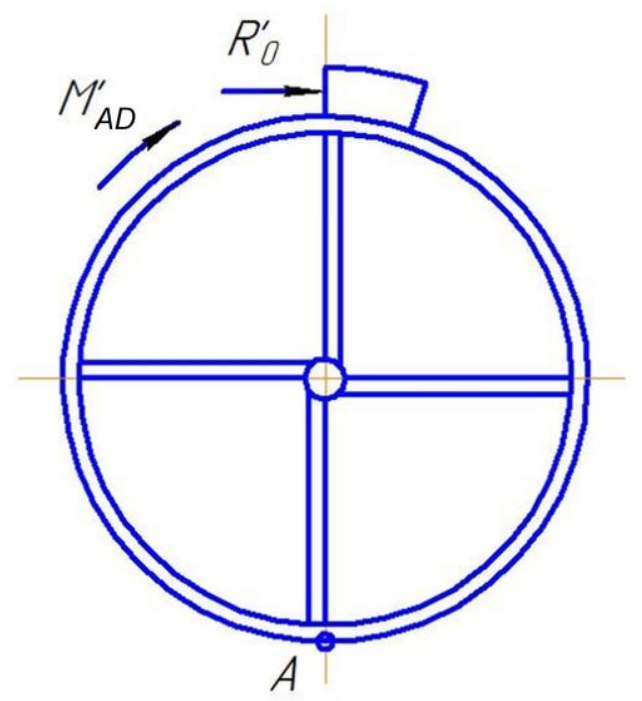

Fig. 5. Calculated scheme of the overturning torque for a four-beam AD.

In this case, the value of the critical overturning torque is determined by the expression:

$$
\begin{gathered}
M_{c r}={M^{\prime}}_{A D}+R_{o}^{\prime}{ }_{o} \cdot D_{g} \\
M_{c r}=162.8+724.2 \cdot 0.64=626.3 \mathrm{Nm}
\end{gathered}
$$


The obtained values of the withdrawal force and the overturning torque are critical and reach such values when the knife is jammed, cutting the helical channel behind the working contour.

\section{Conclusion}

When the geokhod moves, critical cutting forces arise, which cause the axis of rotation of the geokhod to deviate from the axis of the working. Such a deviation requires constant monitoring of the trajectory and making adjustments to the geokhod movement.

With the regular movement of the geokhod in the geo-environment, the values of the withdrawal force and overturning torque will fluctuate from zero to maximum values, which depend on many factors. Therefore, in the design calculations of the geokhod, it is necessary to assess the impact of the emerging overturning forces on the trajectory of the geokhod movement.

\section{References}

1. S.L. Chen, Three-dimensional analysis of earth pressure balance (EPB) shield tunneling in soft bedrock (CSM, Vancouver, 2018)

2. B. Dziuban, H.I. Ling, L. Li, Transp. Infrastructure. Geotech. 5, 318 (2019)

3. C.J. Lee, Y.J. Jeon, S.H. Kim, I.J. Park, Geom. and Eng. J. 11(4), 553 (2016)

4. R.A. Raid, S.A. Madhat, I.A. Osamah, Studia Geot. Mech. 41(2), 102 (2019)

5. A.Z. Waad, A.M. Qasim, H.M. Halah, J. of Eng. Sci. 12(4), 50 (2019)

6. A.B. Efremenkov, IFOST-2011, 2(1), 348 (2011)

7. A.A. Kazantsev, V.P. Kosykh, A.F. Revuzhenko, IOP Conference Series: Materials Science and Engineering, 91, 012089 (2015)

8. M.Y. Blashchuk, A.A. Kazantsev, R.V. Chernukhin, Appl. Mech. Mater. 682, 418 (2014)

9. A.A. Khoreshok, P.V. Buyankin, A.V. Vorobiev, A.A. Dronov, IOP Conference Series: Materials Science and Engineering, 127, 012014 (2016)

10. S. Nishi, T. Seiki, Mem. Sch. Eng. Nagoya Univ., 1, 34 (1997)

11. B. Maidl, L. Schmid, W. Ritz, M. Herrenknecht, Hardrock Tunnel Boring Machines (Ernst\&Sohn, Berlin, 2008)

12. A. A. Khoreshok, L. E. Mametev, A. Yu. Borisov, A. V. Vorobev, Applied Mechanics and Materials, 770, 434 (2015)

13. A. Khoreshok, K. Ananyev, A. Ermakov, E. Golikova, E3S Web Conf. 105, 03010 (2019)

14. A. Khoreshok, K. Ananyev, A. Ermakov, A. Babarykin, E3S Web Conf. 105, 03007 (2019)

15. A. Khoreshok, L. Mametyev, A. Borisov, A. Vorobiev, Stress-deformed state knots fastening of a disk tool on the crowns of roadheaders. Mining 2014. Taishan academic forum - project on mine disaster prevention and control. Chinese coal in the XXI century: Mining, green and safety. Qingdao, China, October 17-20, 2014 (Atlantis press, Amsterdam-Paris-Beijing, 2014)

16. V.Yu. Timofeev, V.Yu. Beglyakov, M.V. Dokhnenko, Applied Mechanics and Materials, 682, 282 (2014) 
17. A. Khoreshok, K. Ananiev, A. Ermakov, A. Babarykin, D. Kuziev, Acta Montanistica Slovaca, 25(1), 70 (2020)

18. V. Kuznetsov, E. Preis, K. Ananyev, A. Ermakov, Determination of contact temperature on cutting disc during rock destruction, E3S WEB OF CONFERENCES. Vth International Innovative Mining Symposium. T.F. Gorbachev Kuzbass State Technical University, 03005 (2020)

19. V. Nesterov, V. Aksenov, V. Sadovets, D. Pashkov, E3S Web Conf. 174, 03011 (2020)

20. V. Aksenov, V. Sadovets, D. Pashkov, E3S Web Conf. 41, 03002 (2018)

21. V.V. Aksenov, A.B. Efremenkov, V.Y. Sadovets, D.A. Pashkov, V.A. Efremenkov, IOP Conference Series: Materials Science and Engineering, 939, 012003 (2020)

22. V.V. Aksenov, A.B. Efremenkov, V.Y. Sadovets, D.A. Pashkov, V.A. Efremenkov, IOP Conference Series: Materials Science and Engineering, 656, 012002 (2019)

23. V. Nesterov, V. Aksenov, V. Sadovets, D. Pashkov, E3S Web Conf. 105, 03001 (2019)

24. V.V. Aksenov, A.B. Efremenkov, V.Y. Sadovets, D.A. Pashkov, IOP Conference Series: Materials Science and Engineering, 441, 012005 (2018) 